\title{
Effects of treatment with butylated hydroxytoluene on the susceptibility of boar spermatozoa to cold stress and dilution
}

\author{
K. Bamba $^{1}$ and D. G. Cran ${ }^{2}$ \\ ${ }^{1}$ Faculty of Agriculture, Shizuoka University, Shizuoka 422, Japan; and ${ }^{2}$ AFRC Institute of Animal \\ Physiology and Genetics Research, Babraham, Cambridge CB2 4AT, UK
}

\begin{abstract}
Summary. Boar spermatozoa acquired resistance to cold shock immediately after exposure to $2 \cdot 0 \mathrm{mmol}$ butylated hydroxytoluene (BHT) $1^{-1}$ when Beltsville thawing solution was used as a basic diluent, as judged by motility (the proportion of motile spermatozoa) and acrosomal integrity. The concentration of BHT could be reduced to $0.2 \mathrm{mmol}^{-1}$ without decreasing the protective action. However, motility was altered in the presence of $>0.15 \mathrm{mmol} \mathrm{BHT}^{-1}$. Beltsville freezing 5 (BF5) diluent was more effective than Beltsville thawing solution in protecting spermatozoa from cold shock, but addition of BHT to BF5 diluent did not affect the motility and acrosomal morphology of spermatozoa before or after cold shock. Dilution of BHT-treated spermatozoa with BF5 diluent did not restore motility and did not afford further protection against cold shock; it was detrimental to spermatozoa treated with 2 mmol BHT $1^{-1}$ for $>15 \mathrm{~min}$. Egg yolk or lecithin had a detrimental effect.

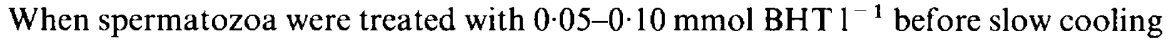
to $5^{\circ} \mathrm{C}$, the progressive motility and acrosomal integrity were maintained better after storage for 6 days than in untreated spermatozoa.
\end{abstract}

Keywords: spermatozoa; cold shock; boar; butylated hydroxytoluene

\section{Introduction}

The antioxidant butylated hydroxytoluene (BHT) provides protection against cold shock in some mammalian spermatozoa (Hammerstedt et al., 1976, 1978; Pursel, 1979; Watson \& Anderson, 1983), but it has been suggested that BHT is unlikely to be of benefit for the cryopreservation of spermatozoa (Pursel, 1979; Watson \& Anderson, 1983).

When boar spermatozoa were incubated at $37^{\circ} \mathrm{C}$ in the presence of $2 \mathrm{mmol} B \mathrm{BT}^{-1}$, the proportion of progressively motile spermatozoa decreased quickly during the initial period (Bamba \& Cran, 1988). The motility-depressing property of BHT is an obstacle to its use as a cryoprotectant of spermatozoa. The present study was to find the optimum conditions of BHT treatment for the maintenance of motility and acrosomal integrity of boar spermatozoa after cold shock and to assess the use of BHT for the storage of semen at $5^{\circ} \mathrm{C}$.

\section{Materials and Methods}

\section{Semen}

Fractions of ejaculate rich and poor in spermatozoa were collected separately from mature boars and cooled to room temperature (approximately $25^{\circ} \mathrm{C}$ ) over $1 \mathrm{~h}$. The concentration of spermatozoa was adjusted to $4 \times 10^{8} \mathrm{ml}^{-1}$ before use in each experiment; the sperm-rich fraction was diluted with seminal plasma that had been prepared 
by centrifuging the sperm-poor fraction at $1200 \mathrm{~g}$ for $20 \mathrm{~min}$. Sperm concentration was determined with a haemocytometer. In each experiment, replicate tests were made on ejaculates from different boars.

\section{Treatment with BHT}

Beltsville thawing solution (BTS; Pursel \& Johnson, 1975) was used as a basic diluent; it consisted of $3.7 \mathrm{~g}$ glucose, $0.6 \mathrm{~g}$ sodium citrate dihydrate, $0.125 \mathrm{~g} \mathrm{NaHCO}_{3}, 0.125 \mathrm{~g}$ EDTA-2Na and $0.075 \mathrm{~g} \mathrm{KCl}$ in $100 \mathrm{ml}$. Dibekacin sulfate (Panimycin: Meiji Seika, Tokyo) was included in BTS at $100 \mu \mathrm{g} \mathrm{ml}^{-1}$. Stock solution of butylated hydroxytoluene (BHT; Sigma) was prepared by dissolving it in absolute dimethyl sulfoxide (DMSO; Sigma, St Louis, MO, USA). Stock solution was added $(2 \%, v / v)$ to basic diluent at $37^{\circ} \mathrm{C}$.

Semen was diluted $1: 1$ with basic diluent containing $\mathrm{BHT}$ at 37 or $25^{\circ} \mathrm{C}$ and incubated for given periods. The final concentration of BHT was nominal because of its extremely low solubility in aqueous media.

\section{Cold shock}

Cold shock was achieved by transferring a glass test tube $(10 \mathrm{~mm} \times 60 \mathrm{~mm})$ containing $0.5 \mathrm{ml}$ semen at $37^{\circ} \mathrm{C}$ to a water bath at $5^{\circ} \mathrm{C}$ and incubating for $10 \mathrm{~min}$.

\section{Assessment of spermatozoa}

Motility. The proportion of motile spermatozoa was estimated by phase-contrast microscopy $(\times 200)$ at $37^{\circ} \mathrm{C}$; $10 \mu \mathrm{l}$ of semen was introduced between a coverslip $(18 \mathrm{~mm} \times 18 \mathrm{~mm})$ and a slide coated with anhydrous caffeine (approximately $20 \mu \mathrm{g} \mathrm{cm}^{-2}$ ).

Acrosomal morphology. Semen was diluted 1:2 or more with BTS containing $0.4 \%(\mathrm{w} / \mathrm{v})$ formaldehyde (formol BTS) at the same temperature as the sample. Cold-shocked samples were diluted with formol BTS at $5^{\circ} \mathrm{C}$. At least 100 spermatozoa were examined under a phase-contrast microscope $(\times 750)$ and the proportion of normal acrosome was estimated. For transmission electron microscopy, samples were processed as described by Cran et al. (1982).

\section{Statistical analysis}

Data were subjected to analyses of variance, and the differences between treatment means were tested by Tukey's procedure (Steel \& Torrie, 1960).

\section{Experiment 1: comparison of basic diluents}

This experiment compared BTS and Beltsville freezing 5 diluent (BF5; Pursel \& Johnson, 1975) as basic diluents in cold shock treatment. BF5 consisted of $1.2 \mathrm{~g} \mathrm{~N}$-Tris(hydroxymethyl)methyl-2-aminomethane sulfonic acid, $0.2 \mathrm{~g}$ Tris(hydroxymethyl)aminomethane, $3.2 \mathrm{~g}$ glucose, $0.5 \mathrm{ml}$ Orvus Es Paste and $20 \mathrm{ml}$ egg yolk in $100 \mathrm{ml}$. Semen samples were diluted $1: 1$ with the basic diluents containing $4.0 \mathrm{mmol} \mathrm{BHT} 1^{-1}$ or $2 \% \mathrm{DMSO}$ at $37^{\circ} \mathrm{C}$ and incubated for 2,15 , 30 and $60 \mathrm{~min}$ before cold shock. Replicate tests were made on four ejaculates.

\section{Experiment 2: effect of dilution with BF5 after BHT treatment}

This experiment was carried out to see whether the motility of BHT-treated spermatozoa could be restored by dilution with BF5. Semen samples were treated with BHT as in Expt 1, before dilution with BF5 (1:4). Replicate tests were made on four ejaculates.

\section{Experiment 3: effect of dilution on BHT-treated spermatozoa}

This experiment was carried out to ascertain the factor(s) responsible for the damage occurring after dilution of BHT-treated spermatozoa with BF5 diluent. Spermatozoa were washed twice with $\mathrm{Ca}^{2+}$-free $\mathrm{Krebs}-\mathrm{Ringer}-$ phosphate buffer, pH 7.4 (KRP; Umbreit et al., 1957). The mixture of 9 volumes of KRP and 1 volume of $5.5 \%$ glucose solution (KRP-G) was used as a basic diluent and washed spermatozoa were resuspended in it to give $4 \times 10^{8}$ cells $\mathrm{ml}^{-1}$. The semen samples were diluted $1:$ I with KRP-G containing 4.0 mmol BHT $1^{-1}$ or $2 \%$ DMSO at $37^{\circ} \mathrm{C}$ and incubated for $30 \mathrm{~min}$. After incubation, the samples were further diluted 1:3 with the following diluents: (1) KRP-G, (2) KRP-G containing $20 \%$ (v/v) egg yolk, (3) KRP-G containing $0 \cdot 15 \%$ (w/v) phosphatidylcholine, (4) KRP-G containing $\left.10.6 \mathrm{mmol} \mathrm{CaCl}\right|^{-1}$ and (5) BF5. To prepare solution 3, $100 \mathrm{mg}$ egg-yolk phosphatidylcholine (Sigma, St Louis, MO, USA) in chloroform was dried under $\mathrm{N}_{2}$ and then dispersed by sonication (ten times for 1 min) into $5 \mathrm{ml}$ distilled water (Ohtake Works, Tokyo; $20 \mathrm{kHz}, 50 \mathrm{~W}$ ). Replicate tests were made on three ejaculates. 


\section{Experiment 4: effect of short-term exposure to BHT}

This experiment investigated the effects of short-term exposure to BHT and the combined effects of BHT treatment and dilution with BF5 diluent. Semen was diluted 1:1 with BTS containing $4.0 \mathrm{mmol} B \mathrm{BT}^{-1}$ at $37^{\circ} \mathrm{C}$. The semen samples were cold-shocked or diluted 1:4 with BF5 diluent after exposure to BHT for $0,0 \cdot 25,0 \cdot 5,1,5$ or $15 \mathrm{~min}$. The samples diluted with BF5 diluent were cold shocked after $1 \mathrm{~min}$ of dilution. In a control sample, semen was diluted 1:1 with BTS containing $2 \%$ DMSO and incubated for $5 \mathrm{~min}$ before cold shock or dilution with BF5. Replicate tests were made on four ejaculates.

\section{Experiment 5: effect of concentration of BHT}

This experiment was to find the optimum concentration of BHT for the maintenance of motility and acrosomal integrity during cold shock and to investigate whether the acquired resistance to cold shock was affected by removing BHT from the sperm environment. Semen was diluted $1: 1$ with BTS containing BHT $(0 \cdot 1,0 \cdot 2,0 \cdot 3,0 \cdot 4,1 \cdot 0,2 \cdot 0$ or $\left.4.0 \mathrm{mmol} 1^{-1}\right)$ or $2 \%$ DMSO at $37^{\circ} \mathrm{C}$ and then cold-shocked after $10 \mathrm{~s}$. Aliquots $(2 \mathrm{ml})$ of BHT treated samples were centrifuged at $300 \mathrm{~g}$ for $10 \mathrm{~min}$ and the supernatant was removed by aspiration. The spermatozoa were then resuspended in a solution of BTS and seminal plasma (I:1) and cold shocked. Replicate tests were made on four ejaculates.

\section{Experiment 6: preservation of BHT-treated spermatozoa at $5^{\circ} \mathrm{C}$}

This experiment investigated whether BHT treatment confers resistance to cold stress during slow cooling and storage at $5^{\circ} \mathrm{C}$. Semen was diluted $1: 1$ with BTS containing BHT $\left(0 \cdot 025,0 \cdot 05,0 \cdot 10,0 \cdot 20\right.$ or $\left.0.30 \mathrm{mmol}^{-1}\right)$ or $2 \%$ DMSO at $25^{\circ} \mathrm{C}$ and then further diluted 1:1 with BTS after $5 \mathrm{~min}$. Diluted semen $(8 \mathrm{ml})$ was placed in a screw-capped test tube $(16.5 \times 105 \mathrm{~mm})$, cooled to $5^{\circ} \mathrm{C}$ over $2 \mathrm{~h}$ and stored for 6 days at $5^{\circ} \mathrm{C}$. During storage, semen was mixed once a day by turning the test tube over several times. Stored semen was incubated for $10 \mathrm{~min}$ at $37^{\circ} \mathrm{C}$ before evaluation of spermatozoa. Replicate tests were made on six ejaculates.

\section{Results}

\section{Experiment 1}

The proportion of motile spermatozoa decreased quickly during incubation at $37^{\circ} \mathrm{C}$ when

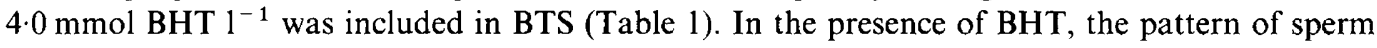
motility was also altered; the amplitude of flagella beat was reduced and most of the motile spermatozoa did not show forward motility. A small reduction in the proportion of normal acrosomes was also observed in the spermatozoa diluted with BTS containing BHT. No visible influence of BHT was noted in the proportion of motile spermatozoa, motility pattern or acrosomal morphology when BF5 was used as a basic diluent. BF5 diluent was more effective than BTS in protecting spermatozoa from cold shock. Addition of BHT to BTS diluent improved motility and acrosomal integrity of cold-shocked spermatozoa, whereas no visible effects of BHT were observed in BF5 diluent. Prolonged incubation at $37^{\circ} \mathrm{C}$ did not increase resistance to cold shock.

\section{Experiment 2}

Addition of BF5 diluent to spermatozoa that had been incubated in the absence of BHT for up to $60 \mathrm{~min}$ had little influence on motility and acrosomal morphology (Table 2). In spermatozoa incubated with BHT for longer than $15 \mathrm{~min}$, highly significant decreases in the percentage of motility and normal acrosomes were observed after dilution with BF5 diluent.

Acrosomes of spermatozoa treated with BHT for $2 \mathrm{~min}$ (Fig. la) were similar in appearance to those treated for $30 \mathrm{~min}$ (Fig. 1b). By electron microscopy, slight signs of damage in the plasma membrane were observed in spermatozoa treated with BHT for $30 \mathrm{~min}$ (Fig. 1c, arrows), but acrosomal integrity was retained in these spermatozoa. In spermatozoa treated with BHT for 2 min, acrosomal morphology was not altered by dilution with BF5 (Fig. Id). However, acrosomal damage occurred immediately when spermatozoa were diluted after treatment with BHT for $30 \mathrm{~min}$ (Fig. 1e and f). The percentages of normal acrosomes in the samples shown in Fig. 1a, b, d and e were $90,89,89$ and 12 , respectively. 

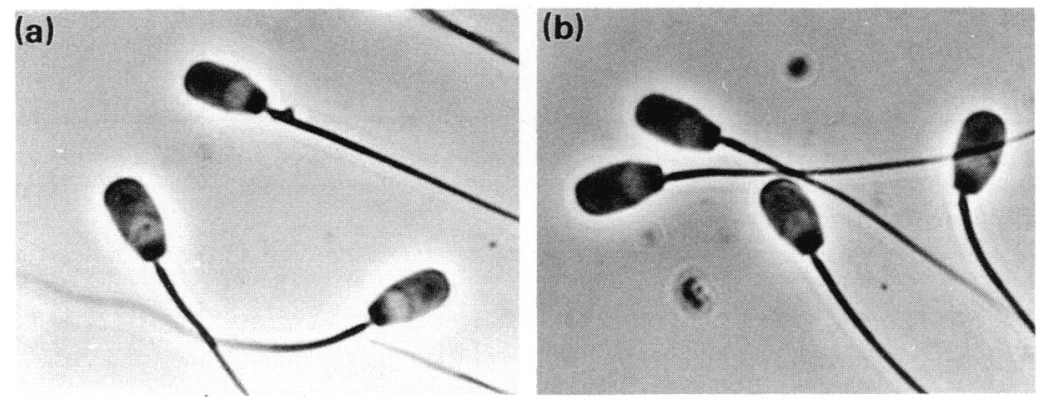

(c)
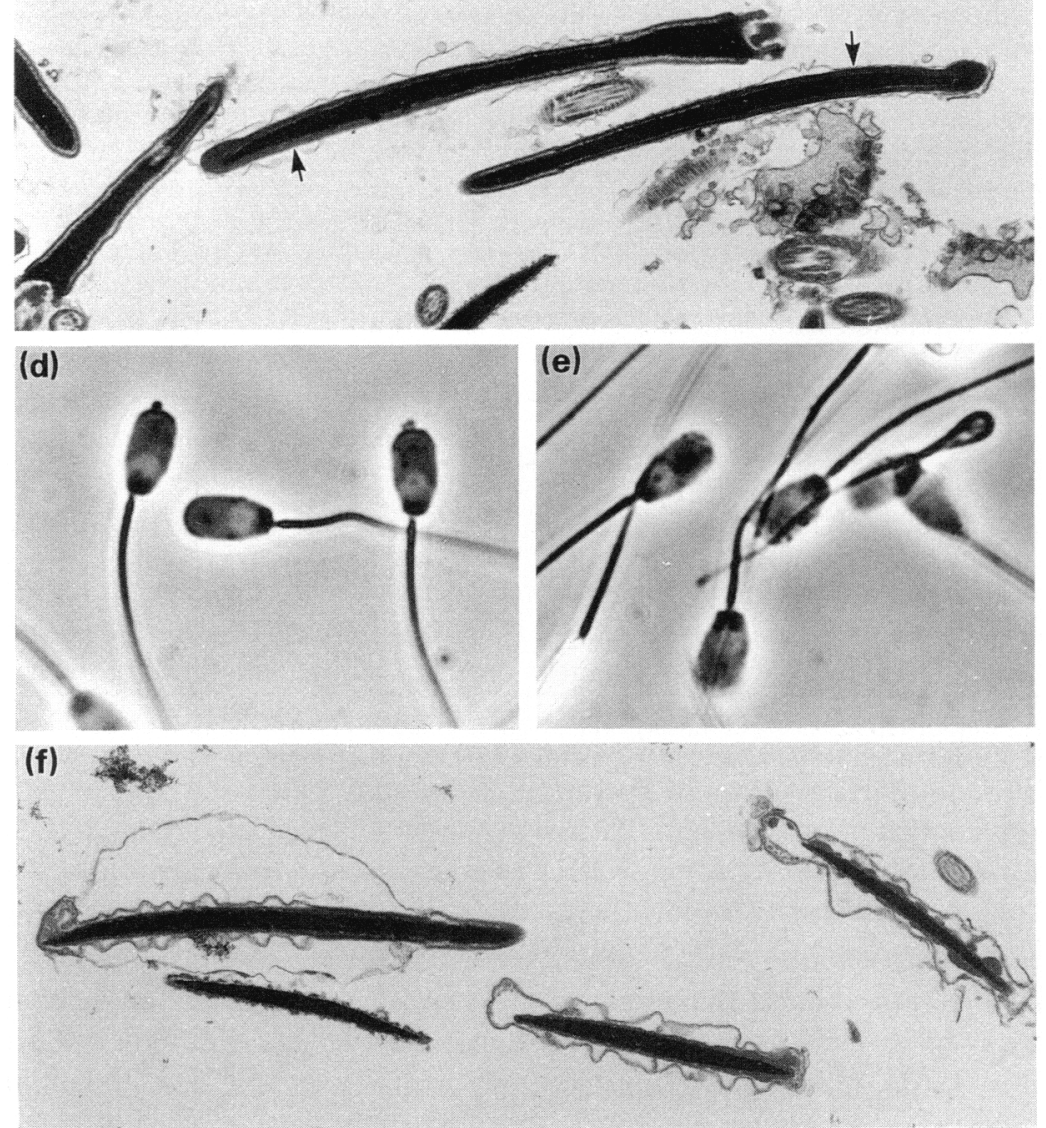

Fig. 1. Boar spermatozoa treated with $2 \mathrm{mmol}$ butylated hydroxytoluene (BHT) $1^{-1}$ for (a) 2 and (b, c) $30 \mathrm{~min}$; or diluted with Beltsville F5 (BF5) after treatment with BHT for (d) 2 and (e, f) $30 \mathrm{~min}$. Most acrosomes remained intact after BHT treatment (a, b, c), but some signs of damage in the plasma membrane were seen by electron microscopy in spermatozoa treated with BHT for 30 min (c, arrows). Spermatozoa diluted with Beltsville F5 after treatment with BHT for (d) 2 and (e, f) $30 \mathrm{~min}$; those shown in (e) and (f) were of similar appearance to those after cold shock. Phase-contrast microscopy, $\times 1000(\mathrm{a}, \mathrm{b}, \mathrm{d}, \mathrm{e})$; transmission electron microscopy, $\times 8000(\mathrm{c}, \mathrm{f})$. 
Table 1. Effects of the diluents Beltsville thawing solution (BTS) and Beltsville F5 (BF5) and butylated hydroxytoluene (BHT) on the percentage of motility and normal acrosomes of boar spermatozoa before and after cold shock

\begin{tabular}{|c|c|c|c|c|c|c|c|c|}
\hline \multirow{3}{*}{$\begin{array}{l}\text { Treatment } \\
\mathrm{A}\end{array}$} & \multirow{3}{*}{$\begin{array}{c}\text { Diluent } \\
\text { BTS }\end{array}$} & \multirow{3}{*}{$\frac{\text { BHT }}{-}$} & \multirow{3}{*}{ 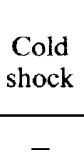 } & \multicolumn{5}{|c|}{ Duration of BHT treatment (min) } \\
\hline & & & & \multicolumn{2}{|c|}{2} & 15 & 30 & 60 \\
\hline & & & & $9 !$ & (96) & $91 \quad(97)$ & $91 \quad(97)$ & (97) \\
\hline B & BTS & + & - & 89 & $(93)^{\mathrm{aCD}}$ & $68^{\mathrm{ACD}}(90)^{\mathrm{ACD}}$ & $60^{\mathrm{ACD}}(87)^{\mathrm{ACD}}$ & $48^{\mathrm{ACD}}(81)^{\mathrm{ACD}}$ \\
\hline $\mathrm{C}$ & BF5 & - & - & 9l & (98) & (98) & (96) & (97) \\
\hline D & BF5 & + & - & 91 & (98) & $89 \quad(97)$ & $88 \quad(96)$ & (97) \\
\hline A & BTS & - & + & \multicolumn{2}{|c|}{$5^{\mathrm{BCD}}(2)^{\mathrm{BCD}}$} & $5^{\mathrm{BCD}}(1)^{\mathrm{BCD}}$ & $5^{\mathrm{BCD}}(0)^{\mathrm{BCD}}$ & $3^{\mathrm{BCD}}(0)^{\mathrm{BCD}}$ \\
\hline B & BTS & + & + & 73 & $(90)$ & (90) & (85) & (78) \\
\hline $\mathrm{C}$ & BF5 & - & + & 74 & $(69)^{\mathrm{b}}$ & $(63)^{b}$ & (59) & (46) \\
\hline $\mathrm{D}$ & BF5 & + & + & 74 & (78) & (74) & (66) & (56) \\
\hline
\end{tabular}

Values are means of four replicates: \% of motility and normal acrosomes (shown in parentheses).

The value bearing superscript letter differs significantly from the value for the treatment abbreviated with the same letter (lower-case letter, $P<0.05$; capital letter, $P<0.01$ ).

Table 2. Effects of dilution with Beltsville F5 (BF5) diluent after treatment with butylated hydroxytoluene (BHT) on the percentage of motility and normal acrosomes of boar spermatozoa

\begin{tabular}{|c|c|c|c|c|c|c|c|}
\hline \multirow[b]{2}{*}{ Treatment } & \multirow[b]{2}{*}{ BHT } & \multirow[b]{2}{*}{ BF5 } & \multicolumn{5}{|c|}{ Duration of BHT treatment (min) } \\
\hline & & & & 2 & 15 & 30 & 60 \\
\hline A & - & - & 91 & (96) & (97) & $91 \quad(97)$ & $91 \quad$ (97) \\
\hline B & + & - & 89 & (93) & $(90)^{\mathrm{ac}}$ & $60^{\mathrm{AC}}(87)^{\mathrm{AC}}$ & $48^{\mathrm{AC}}$ \\
\hline $\mathrm{C}$ & - & + & 91 & (96) & (96) & $91 \quad(95)$ & $91 \quad(96)$ \\
\hline D & + & + & 81 & $(87)^{\mathrm{ac}}$ & $28^{\mathrm{ABC}}(69)^{\mathrm{ABC}}$ & $13^{\mathrm{ABC}}(54)^{\mathrm{ABC}}$ & $1^{\mathrm{ABC}}(21)^{\mathrm{ABC}}$ \\
\hline
\end{tabular}

Values are means of four replicates: \% of motility and normal acrosomes (shown in parentheses).

The value bearing superscript letter differs significantly from that for the treatment abbreviated with the same letter (lower-case letter, $P<0.05$; capital letter, $P<0.01$ ).

\section{Experiment 3}

Addition of diluents containing egg yolk to washed spermatozoa incubated without BHT caused an increase in motility, but acrosomal morphology was little influenced by the diluents (Table 3). In BHT-treated spermatozoa, addition of KRP-G containing egg yolk or phosphatidylcholine caused a significant decrease in motility and percentage of normal acrosomes.

\section{Experiment 4}

Incubation of spermatozoa with BHT for up to $30 \mathrm{~s}$ had little influence on motility, but during subsequent incubation motility declined (Table 4). Acrosomal morphology was not influenced appreciably during incubation. Resistance to cold-shock damage was induced by brief exposure to BHT. In spermatozoa treated with BHT for $15 \mathrm{~min}$, dilution with BF5 diluent caused a significant decrease in motility and percentage of normal acrosomes. The use of BF5 diluent after BHT treatment did not improve the acrosomal integrity of cold-shocked spermatozoa. 
Table 3. Effects of dilution with various diluents after treatment with butylated hydroxytoluene (BHT) on the percentage of motility and normal acrosomes of boar spermatozoa

\begin{tabular}{|c|c|c|c|}
\hline \multirow[b]{2}{*}{ Treatment } & \multirow[b]{2}{*}{ Diluent } & \multicolumn{2}{|c|}{ BHT treatment } \\
\hline & & - & + \\
\hline A & Before dilution & $43 \quad(97)$ & $30 \quad(89)$ \\
\hline B & Krebs-Ringer-phosphate ${ }^{1}$ & & \\
\hline & + glucose $(\mathrm{KRP}-\mathrm{G})$ & $43 \quad(97)$ & $14 \quad(76)$ \\
\hline $\mathrm{C}$ & KRP-G $+20 \%$ egg yolk & $83 \quad(94)$ & $3^{A}(47)^{A b E}$ \\
\hline $\mathrm{D}$ & KRP-G $+0.15 \%$ lecithin & $57 \quad(96)$ & $7^{\mathrm{a}}(48)^{\mathrm{AbE}}$ \\
\hline E & $\mathrm{KRP}-\mathrm{G}+10.6 \mathrm{mmol} \mathrm{CaCl}_{2} \mathrm{1}^{-1}$ & $33^{\text {cf }}(93)$ & $10 \quad(82)$ \\
\hline $\mathbf{F}$ & Beltsville F5 & 87 (94) & $13(50)^{\mathrm{AbE}}$ \\
\hline
\end{tabular}

Values are means of three replicates: \% of motility and normal acrosomes (shown in parentheses).

The value bearing superscript letter differs significantly from that for the treatment abbreviated with same letter (lower-case letter, $P<0.05$; capital letter, $P<0.01)$.

${ }^{1} \mathrm{Ca}^{2+}$-free.

Table 4. Effects of duration of treatment with butylated hydroxytoluene (BHT) and dilution with Beltsville F5 (BF5) after BHT treatment on the percentage of motility normal acrosomes of boar spermatozoa before and after cold shock

\begin{tabular}{|c|c|c|c|c|c|}
\hline \multirow[b]{2}{*}{ Treatment } & \multirow[b]{2}{*}{$\begin{array}{l}\text { Duration of } \\
\text { BHT treatment }\end{array}$} & \multicolumn{2}{|c|}{ BHT treatment alone } & \multicolumn{2}{|c|}{ BHT treatment + BF5 diluent } \\
\hline & & $\begin{array}{c}\text { Before } \\
\text { cold shock }\end{array}$ & $\begin{array}{c}\text { After } \\
\text { cold shock }\end{array}$ & $\begin{array}{c}\text { Before } \\
\text { cold shock }\end{array}$ & $\begin{array}{c}\text { After } \\
\text { cold shock }\end{array}$ \\
\hline A & Instant & $89^{\mathrm{EF}}(97)$ & $63^{G}(91)^{G}$ & $90^{F} \quad(97)^{F}$ & $78^{\mathrm{F}}(71)^{\mathrm{eF}}$ \\
\hline B & $15 \mathrm{~s}$ & $86^{\mathrm{eF}}(97)$ & $64^{G}(86)^{G}$ & $89^{\mathrm{F}} \quad(96)^{\mathrm{F}}$ & $69^{\mathrm{F}} \quad(65)^{\mathrm{F}}$ \\
\hline $\mathrm{C}$ & $30 \mathrm{~s}$ & $86^{\mathrm{eF}}(98)$ & $56^{\mathrm{G}}(90)^{\mathrm{G}}$ & $89^{F} \quad(96)^{F}$ & $73^{F} \quad(68)^{F}$ \\
\hline D & $1 \mathrm{~min}$ & $76^{f} \quad(98)$ & $54^{\mathrm{G}}(88)^{\mathrm{G}}$ & $90^{\mathrm{F}} \quad(97)^{\mathrm{F}}$ & $73^{F} \quad(69)^{F}$ \\
\hline $\mathrm{E}$ & $5 \mathrm{~min}$ & $61 \quad(96)$ & $53^{\mathrm{G}}(85)^{\mathrm{G}}$ & $83^{\mathrm{F}} \quad(91)^{\mathrm{F}}$ & $59^{\mathrm{F}} \quad(51)^{\mathrm{f}}$ \\
\hline F & $15 \mathrm{~min}$ & $45 \quad(95)$ & $46^{G}(85)^{G}$ & $41 \quad(78)$ & $24 \quad(27)$ \\
\hline $\mathrm{G}$ & $\begin{array}{l}\text { Control } \\
\text { (5 min without } \mathrm{BHT})\end{array}$ & $89^{\mathrm{EF}}(98)$ & (2) & $89^{F} \quad(96)^{F}$ & $74^{F}(78)^{E F}$ \\
\hline
\end{tabular}

Values are means of four replicates: \% of motility and normal acrosomes (shown in parentheses).

The value bearing superscript letter differs significantly from that for the treatment abbreviated with the same letter (lower-case letter, $P<0.05$; capital letter, $P<0.01$ ).

\section{Experiment 5}

When spermatozoa were cold shocked after exposure to BHT for $10 \mathrm{~s}$, the protective effect of BHT was similar at concentrations between 2.0 and $0.2 \mathrm{mmol}^{-1}$, as judged by motility (Table 5). For the protection of acrosomes, the effect of BHT was similar at concentrations between $2 \cdot 0$ and $0.1 \mathrm{mmol} \mathrm{l}^{-1}$. After removal of added BHT, the protective effect against cold shock was retained; the removal of BHT $\left(0 \cdot 5-2 \cdot 0 \mathrm{mmol}^{-1}\right)$ resulted in a slight decrease in motility and percentage of normal acrosomes after cold shock.

\section{Experiment 6}

Significantly higher percentages of motility and normal acrosomes were observed in spermatozoa

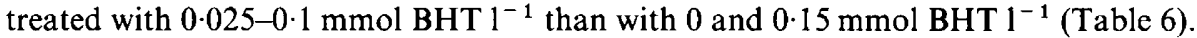


Table 5. Effects of concentration of butylated hydroxytoluene (BHT) and removal of BHT on the percentage of motility and normal acrosomes of boar spermatozoa before and after cold shock

\begin{tabular}{|c|c|c|c|c|c|c|}
\hline \multirow{3}{*}{$\begin{array}{l}\text { Treatment } \\
\mathrm{A}\end{array}$} & \multirow{3}{*}{$\begin{array}{c}\begin{array}{c}\mathrm{BHT}^{*} \\
\left(\mathrm{mmoll}^{-1}\right)\end{array} \\
0\end{array}$} & \multicolumn{3}{|c|}{ In the presence of BHT } & \multicolumn{2}{|c|}{ After removal of BHT } \\
\hline & & \multicolumn{2}{|c|}{$\begin{array}{l}\text { Before } \\
\text { cold shock }\end{array}$} & $\begin{array}{c}\text { After } \\
\text { cold shock }\end{array}$ & $\begin{array}{l}\text { Before } \\
\text { cold shock }\end{array}$ & $\begin{array}{c}\text { After } \\
\text { cold shock }\end{array}$ \\
\hline & & 90 & (98) & (1) & $(98)$ & (1) \\
\hline B & 0.05 & 90 & (98) & $(53)^{\mathbf{A}}$ & (97) & $(35)^{A}$ \\
\hline $\mathrm{C}$ & $0 \cdot 10$ & 90 & (98) & $42^{\mathrm{AB}}(89)^{\mathrm{AB}}$ & (97) & $43^{\mathrm{AB}}(75)^{\mathrm{AB}}$ \\
\hline D & $0 \cdot 15$ & 90 & (97) & $63^{\mathrm{ABC}}(93)^{\mathrm{AB}}$ & (93) & $62^{\mathrm{AB}}(82)^{\mathrm{AB}}$ \\
\hline $\mathrm{E}$ & 0.20 & 83 & (96) & $67^{\mathrm{ABC}}(95)^{\mathrm{AB}}$ & $(91)^{a}$ & $67^{\mathrm{ABc}}(86)^{\mathrm{AB}}$ \\
\hline $\mathrm{F}$ & 0.50 & 80 & (96) & $72^{\mathrm{ABC}}(95)^{\mathrm{AB}}$ & $67^{\mathrm{ABC}}(89)^{\mathrm{A}}$ & $67^{\mathrm{ABc}}(86)^{\mathrm{AB}}$ \\
\hline G & 1.00 & 80 & (98) & $72^{\mathrm{ABC}}(95)^{\mathrm{AB}}$ & $67^{\mathrm{ABC}}(89)^{\mathrm{A}}$ & $63^{\mathrm{ABc}}(87)^{\mathrm{AB}}$ \\
\hline $\mathrm{H}$ & 2.00 & 80 & (97) & $72^{\mathrm{ABC}}(94)^{\mathrm{AB}}$ & $67^{\mathrm{ABC}}(90)^{\mathrm{a}}$ & $63^{\mathrm{ABc}}(85)^{\mathrm{AB}}$ \\
\hline
\end{tabular}

Values are means of four replicates: \% of motility and normal acrosomes (shown in parentheses).

The value bearing superscript letter differs significantly from that for the treatment abbreviated with the same letter (lower-case letter, $P<0.05$; capital letter, $P<0.01$ ).

*Concentrations of BHT are expressed as those at the time of BHT treatment.

Table 6. Effects of treatment with butylated hydroxytoluene (BHT) on the percentage of motility and normal acrosomes of boar spermatozoa after storage for 6 days at $5^{\circ} \mathrm{C}$

\begin{tabular}{lcll}
\hline Treatment & $\begin{array}{c}\mathrm{BHT}^{*} \\
\left(\mathrm{mmoll}^{-1}\right)\end{array}$ & $\%$ motility & $\begin{array}{c}\% \text { normal } \\
\text { acrosomes }\end{array}$ \\
\hline $\mathrm{A}$ & 0 & $50 \pm 25$ & $45 \pm 28$ \\
$\mathrm{~B}$ & 0.0125 & $63 \pm 23$ & $62 \pm 26^{\mathrm{A}}$ \\
$\mathrm{C}$ & 0.025 & $73 \pm 13^{\mathrm{af}}$ & $69 \pm 25^{\mathrm{AF}}$ \\
$\mathrm{D}$ & 0.05 & $79 \pm 4^{\mathrm{AF}}$ & $71 \pm 23^{\mathrm{AF}}$ \\
E & 0.1 & $77 \pm 6^{\mathrm{AF}}$ & $74 \pm 17^{\mathrm{AF}}$ \\
F & $0 \cdot 15$ & $50 \pm 28$ & $51 \pm 28$ \\
\hline
\end{tabular}

Values are mean \pm sD for six replicates.

The value bearing superscript letter differs significantly from that for the treatment abbreviated with same letter (lower-case letter, $P<0.05$; capital letter, $P<0.01$ ).

*Concentrations of BHT are expressed as those at the time of BHT treatment.

\section{Discussion}

Butylated hydroxytoluene is soluble in ethanol, DMSO and fats, but not in water. In the present study, BHT was first dissolved in DMSO (stock solution). When the stock solution was added to BTS solution at $2 \%$, a milky precipitate was observed, suggesting that a considerable amount of the BHT was not fully in solution. Hammerstedt et al. (1976) deposited a thin film of BHT on a test tube wall by evaporating ethanol containing BHT; a sperm suspension was then added to the tube and mixed to permit uptake of BHT by spermatozoa. In this method, spermatozoa would take up BHT through direct contact with the film of BHT.

As shown in Expt 1, the motility of spermatozoa was reduced in the presence of $2 \mathrm{mmol}$ BHT $1^{-1}$ when BTS was used as a basic diluent. However, using the method of Hammerstedt et al. (1976), Pursel (1979) reported only a slight depression of motility after treatment with 
$0 \cdot 1-2 \cdot 0 \mathrm{mmol}$ BHT $1^{-1}$. Thus, it seems likely that the uptake of BHT by spermatozoa is influenced appreciably by the method of its application.

Killian et al. (1989) found that the concentrations of BHT that reduced the motility of bovine spermatozoa were lower in skimmed milk diluent than in whole milk diluent. Pursel (1979) also suggested that BHT did not act synergistically with BF5 diluent for the protection of boar sperma-

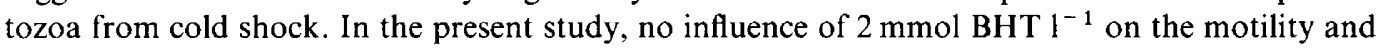
acrosomal integrity was observed when BF5 was used as a basic diluent. It is therefore thought that BHT binds to lipids in egg yolk or whole milk and that the effective concentration of BHT or free BHT is negligible in the diluents containing lipids. The sperm concentration at the time of BHT treatment would be another important factor influencing the optimum concentration of BHT, because sperm cells contain considerable amounts of lipids. This was why the sperm concentration was constant in the present study.

In Expt 2, BF5 diluent was added to BHT-treated spermatozoa to examine whether the altered motility patterns could be restored by adsorbing BHT to the egg yolk component that showed high affinity to the drug, but BF5 diluent had no such effect. Hammerstedt et al. (1976) reported that BHT was tightly bound to the spermatozoa and was not removed by repeated washing. Once BHT binds to spermatozoa, irreversible changes occur in sperm physiology. The addition of BF5 diluent caused an abrupt rupture of membranes in spermatozoa that had been treated with 2 mmol BHT $1^{-1}$ for $>15$ min. Ultrastructural examination by transmission electron microscopy showed that the change was similar to that of cold-shocked spermatozoa (Bamba \& Cran, 1985). Diluents containing egg yolk or phosphatidylcholine (lecithin) showed similar detrimental effects, indicating that lecithin is mainly responsible for the phenomenon. However, calcium ions did not participate in the phenomenon. Prolonged exposure of boar spermatozoa to $2 \mathrm{mmol} \mathrm{BHT} 1^{-1}$ had an adverse effect on survival and rendered the membranes susceptible to egg yolk. Snipes et al. (1975) reported that BHT acted as an antiviral agent to some lipid-containing viruses. Hammerstedt et al. (1976) found that BHT was taken up by bovine spermatozoa and caused an apparent increase in membrane fluidity; the protective action of BHT against cold shock is attributed to the increased fluidity of membranes. It is possible that the membrane structure cannot be maintained when fluidity increases beyond a certain level. Although the mechanism of the protective action of lecithin against cold shock is uncertain, the possibility of modification of membrane fluidity must be considered. When lecithin interacts with BHT-treated membranes, the membrane fluidity may immediately increase beyond a critical level, leading to membrane rupture. In the present study, boar spermatozoa acquired resistance against cold shock immediately after exposure to $2 \mathrm{mmol}$ BHT $1^{-1}$. Since spermatozoa exposed to $2 \mathrm{mmol} \mathrm{BHT} 1^{-1}$ for up to $1 \mathrm{~min}$ were not influenced by dilution with BF5 diluent, it would appear that egg yolk may not be detrimental to membranes with increased fluidity. However, treatment with BHT before dilution with BF5 did not increase resistance to cold shock.

Hammerstedt et al. (1978) found that treatment of rabbit spermatozoa with $0.5 \mathrm{mmol} \mathrm{BHT}^{-1}$ had no effect on fertilizing capacity. Pursel (1979) showed that boar spermatozoa treated with

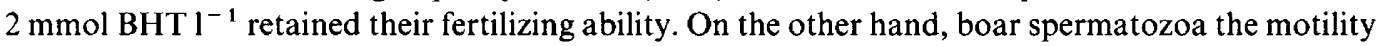
patterns of which had been altered by BHT showed extremely low fertilizing ability in vitro (K. Inoue \& K. Bamba, unpublished observation). BHT treatment should therefore be carried out avoiding the alteration in motility patterns, if the aim of the treatment is storage of spermatozoa. In Expt 5, motility patterns were not altered in the presence of $<0.15 \mathrm{mmol} \mathrm{BHT} \mathrm{l}^{-1}$, but the protective effect against cold shock was reduced.

Storage of liquid boar semen at $5^{\circ} \mathrm{C}$ is more convenient than at $15^{\circ} \mathrm{C}$ because a conventional refrigerator can be used. The temperature of the semen can be easily maintained at $5^{\circ} \mathrm{C}$ by using iced water during transport. However, boar semen is usually stored at temperatures between 15 and $20^{\circ} \mathrm{C}$ using diluents such as BTS. The result of Expt 6 demonstrated that motility and acrosomal integrity were well maintained during storage for 6 days at $5^{\circ} \mathrm{C}$ when spermatozoa were treated with $0 \cdot 05-0 \cdot 1 \mathrm{mmol} \mathrm{BHT} 1^{-1}$ before storage. The optimum concentrations of BHT for storage at 
$5^{\circ} \mathrm{C}$ were lower than for protection from cold shock; the decrease in protective action against cold shock might be compensated for by slow cooling. It is therefore thought that a slight increase in membrane fluidity, which is insufficient for the protection from cold shock, is satisfactory for the maintenance of membrane functions during storage at $5^{\circ} \mathrm{C}$.

According to Kampschmidt et al. (1953), egg yolk has two main benefits: as a protective factor that allows protection from cold stresses and allowing the maintenance of viability during storage. The results of this study indicate that BHT could be substituted for at least the protective factor. It is possible that BHT contributes, in part, to the protection of spermatozoa during prolonged storage at $5^{\circ} \mathrm{C}$ through its antioxidizing action. Although the mechanism by which BHT protects spermatozoa from cold stress has not been fully elucidated, the present study provided evidence that BHT can be used as a cryoprotectant of boar semen. However, further studies are required to establish a practical technique for the storage of boar semen at $5^{\circ} \mathrm{C}$ by the use of BHT and to compare the use of this storage method with conventional methods (storage at $15-20^{\circ} \mathrm{C}$ ).

Killian et al. (1989) showed that in freezing bull semen, the addition of BHT to milk diluent resulted in higher motility after thawing. However, Pursel (1979) suggested that the use of BHT for freezing of boar semen was not promising. The present study showed the possibility that diluents containing egg yolk exert detrimental effects on BHT-treated spermatozoa. On the other hand, spermatozoa of poultry are highly resistant to cold shock and can be successfully frozen by the use of diluent free from egg yolk (Lake \& Stewart, 1978). Thus, it is worthwhile testing the suitability of diluents free from egg yolk for freezing BHT-treated boar spermatozoa.

We thank Shizuoka Prefectural Swine and Poultry Experimental Station for providing the samples of boar semen. We are also grateful to $\mathbf{H}$. Ikeda for assistance with photographic techniques.

\section{References}

Bamba, K. \& Cran, D.G. (1985) Effect of rapid warming of boar semen on sperm morphology and physiology. Journal of Reproduction and Fertility 75, 133-138.

Bamba, K. \& Cran, D.G. (1988) Further studies on rapid dilution and warming of boar semen. Journal of Reproduction and Fertility 82, 509-518.

Cran, D.G., Dott, H.M. \& Wilmington, J.W. (1982) The structure and formation of rolled and crested bull spermatozoa. Gamete Research 5, 263-269.

Hammerstedt, R.H., Amann, R.P., Rucinsky, T., Morse, P.D., II, Lepock, J., Snipes, W. \& Keith, A.D. (1976) Use of spin labels and electron resonance spectroscopy to characterize membranes of bovine sperm: effect of butylated hydroxytoluene and cold shock. Biology of Reproduction 14, 381-397.

Hammerstedt, R.H., Keith, A.D., Snipes, W., Amann, R.P., Arruda, D. \& Griel, L.C., Jr (1978) Use of spin labels to evaluate effects of cold shock and osmolality on sperm. Biology of Reproduction 18, 686-696.

Kampschmidt, R.F., Mayer, D.T. \& Herman, H.A. (1953) Lipid and lipoprotein constituents of egg yolk in the resistance and storage of bull spermatozoa. Journal of Dairy Science 36, 733-742.

Killian, G., Honadel, T., McNutt, T., Henault, M., Wegner, C. \& Dunlap, D. (1989) Evaluation of butylated hydroxytoluene as a cryopreservative added to whole or skim milk diluent for bull semen. Journal of Dairy Science 72, 1291-1295.

Lake, P.E. \& Stewart, J.M. (1978) Preservation of fowl semen in liquid nitrogen -an improved method. British Poultry Science 19, 187-194.

Pursel, V.G. (1979) Effect of cold shock on boar sperm treated with butylated hydroxytoluene. Biology of Reproduction 21, 319-324.

Pursel, V.G. \& Johnson, L.A. (1975) Freezing of boar spermatozoa: fertilizing capacity with concentrated semen and a new thawing procedure. Journal of Animal Science 40, 99-102.

Snipes, W., Person, S., Keith, A. \& Cupp, J. (1975) Butylated hydroxytoluene inactivates lipid-containing viruses. Science, NY 88, 64-66.

Steel, R.G.D. \& Torrie, J.H. (1960) Principles and Procedures of Statistics. McGraw-Hill Book Co., New York.

Umbreit, W.W., Burris, R.H. \& Stauffer, J.F. (1957) Manometric Techniques, revised edn. Burgess Publishing Co., Minneapolis.

Watson, P.F. \& Anderson, W.J. (1983) Influence of butylated hydroxytoluene (BHT) on the viability of ram spermatozoa undergoing cold shock. Journal of Reproduction and Fertility 69, 229-235.

Received 22 January 1991 